\title{
Imagem Atual do Ministério do Trabalho e Previdência Social
}

\section{AYRTON ACHÉ PILLAR}

SUMARIO : Diretrizes Gerais do MTPS; Uma Equipe a Serviço do Trabalhador; A Valorização do Homem, como Filosofia Básica de um Governo; Sentido Geral dos Problemas; O Programa de Integração Social (PIS); O Programa de Formação do Patrimônio do Servidor Público (PASEP); O Programa de Valorização da Ação Sindical; O Sindicato Ideal; O Programa Nacional de Valorização do Trabalhador (PNVT); O Programa de Valorização do Trabalhador Rural; Política Salarial; Salário Mínimo; Salário Suplementar; Programa Especial de Bolsas de Estudo PEBE; Segurança e Higiene do Trabalho; Grupo-Tarefa da Amazônia - GTA; Conclusão.

\section{DIRETRIZES GERAIS DO MINISTÉRIO DO TRABALHO E PREVIDÊNCIA SOCIAL}

A diferença essencial entre o que se fazia, antes de março de 1964, no MINISTÉRIO DO TRABALHO E PREVIDÊNCIA SOCIÁL € o que se faz agora é, simplesmente, uma diferença de filosofia de Governo.

Trabalhadores e empresários, antes, eram meio, eram instrumento, eram massa de manobra. Agora, o empresário e o trabalhador são olhados como um fim, para o qual tendemos com a mira na valorização do homem, valorização progressiva a ser con. seguida pela harmonia entre o capital e o trabalho, pela implantação da justiça social, entendida como distribuição equânime da riqueza coletiva, e pelo esforço conjugado em prol do bem comum.

de Estas são as frases que dão abertura à exposição de fatos e ter números que faremos a seguir e através dos quais se poderá Previda visão do dinamismo do atual Ministério do Trabalho e Previdência Social.

Na maneira de agir da nova administração está contida toda uma teoria política, mas que seria letra morta, como o foi em ou-
tros tempos, se a idéia não se concretizasse na realidade, o dogma 
não se objetivasse na liturgia e a diretriz geral não se traduzisse, pragmaticamente, nas linhas de ação cotidiana (Júlio Barata ESG - 1970). E a confirmação desse procedimento encontra prova positiva no clima de paz social que o Brasil vem desfrutando durante o Governo da Revolução de 1964.

\section{UMA EQUIPE A SERVIÇO DO TRABALHADOR}

Para que se possa avaliar a atuação do MTPS em favor da consolidação da política social da Revolução, nestes quase quatro anos e meio da gestão do Prof. Júlio Barata, mister se faz enfatizar o cuidado com que o titular da Pasta do Trabalho escolheu a sua equipe de auxiliares. Nessa escolha prevaleceu como determinante básica não apenas a capacidade técnica, mas o entusiasmo patriótico que os escolhidos devotam à causa pública.

É de justiça salientar que nesse trabalho de verdadeira ga. rimpagem buscou-se, em primeiro lugar, valorizar o servidor do MTPS. E este correspondeu, plenamente, ao que dele se esperava.

Assim, em pouco tempo, coordenou-se a equipe técnico-administrativa que, até os dias de hoje, sem solução de continuidade, vem programando, pesquisando, supervisionando e avaliando os programas de trabalho idealizados pelo Titular da Pasta.

\section{A VALORIZAÇÃO DO HOMEM, COMO FILOSOFIA BÁSICA DE UM GOVERNO}

"O Estado deve existir para o homem, e não o homem pa. ra o Estado: eis a máxima, muitas vezes repetida, que se identifica com outra : a filosofia básica de um Governo deve ser a valorização do homem, primeiro capital de uma nação e supremo inves-
timento de um povo".

Estas palavras se contêm na Aula Magna que o Ministro Júlio Barata proferiu na Universidade Federal da Bahia a 8 de março
de 1972. E disse mais:

"O signo do Estado Moderno, apto à realização de seus fins, é um só : a valorização do homem, isto é, a subordinação de cada iniciativa do poder público ao bem-estar de cada indivíduo e
de cada família".

"Para isso, num plano abstrato e de idéias gerais, faz-se mister contemplar o homem como pessoa, isto é, na fórmula clássica, individuum subsistens rationalis naturae, e não como simples objeto, número ou coisa; reconhecer o caráter social do ser R. Serv. públ., Brasilia, 109 (2) abr./jun. 1974 
humano, obrigado, por sua própria condição social, à convivência, à solidariedade e à comunhão com outros seres; ver no homem, enfim, ao lado de seu valor econômico, como força de trabalho, o seu valor moral e cívico, como célula viva de um tecido inconsútil, a Pátria, e, em função desse valor, que lhe é intrínseco, estruturar e dinamizar a política, a economia e toda a vida nacional.

Valorizar o homem não significa apenas avaliar-Ihe o peso ontológico na série dos bens criados. Significa, também e principalmente, aumentar-lhe o valor em todos os sentidos, conferindothe, além dos direitos humanos essenciais, o direito ao trabalho e, pelo trabalho, a participação constante e perene nos frutos do progresso que, para fazer jus à denominação, há de ser o progresso coletivo, ou seja, o enriquecimento comum".

Estas assertivas hão de ser corroboradas na medida em que, baseadas em dados corretos e reais, nos detivermos na anás lise particularizada de cada um dos Programas em curso de execução.

\section{SENTIDO GERAL DOS PROGRAMAS}

"Todos quantos vivem do trabalho, na cidade ou no campo, a serviço das empresas ou do Governo, foram compreendidos no vasto âmbito de uma programação, cuja finalidade é a de construir uma sociedade aberta, para a qual todos contribuam e da qual todos participem, com iguais oportunidades para todos, com equilibrio e harmonia entre patrões e empregados e sem lutas de classe".

O observador que se debruçar sobre o elenco de programas do Ministério do Trabalho e Previdência Social notará que, tanto no Programa de Integração Social ou PIS, quanto no Programa de Formação do Patrimônio do Servidor Público ou PASEP; no Programa de Valorização da Ação Sindical; no Programa Nacional de Valorização do Trabalhador ou PNVT; no Programa de Assistên. cia ao Trabalhador Rural ou PRORURAL, o sentido desses Progra. mas é o de uma mobilização nacional em prol da valorização do homem. Toda a força do trabalho do País, em todos os seus níveis e setores, é objeto de uma série de planos e medidas, com o fito de obter para a coletividade, de par com o rendimento eco. nômico, a melhoria social.

E ainda o Ministro Júlio Barata quem esclarece:

"Os programas do Ministério do Trabalho e Previdência So- 
gânica, a denunciar a preocupação de atingir a democracia humanista ou o capitalismo do grande número, e, ao mesmo tempo, revelam adequação com a realidade brasileira, e portanto, exeqüibilidade, não se tratando, como não se trata, de planos de fachada, utópicos ou impraticáveis".

O Ministério do Trabalho e Previdência Social foi buscar em pronunciamentos do Presidente MÉDICI o espírito da política social do Governo, conforme palavras de 6 de janeiro de 1970 :

"Sem quebra do desenvolvimento econômico do País, cujo ritmo se deve, não só manter, mas, ainda, acelerar tanto quanto possível, impõe-se, concomitantemente, a adoção de medidas pelas quais se venha a distribuir a renda global de modo mais equâ. nime, a fim de que todas as camadas da população sejam beneficiadas pelo aumento da riqueza comum".

O desafio, oferecido à área econômica e à área social, consiste, como se vê, na manutenção de um paralelismo permanente entre o esforço para o crescimento da riqueza material e para a utilização dela como meio e modo de beneficiar o homern, fazendo.o partilhar dos frutos do processo.

A filosofia do Governo implica também o emprego maciço da política de desenvolvimento social como forma de aumentar a renda dos grupos assalariados.

Significa, por conseguinte, criar modalidades novas e múltiplas para fomentar a poupança do trabalhador, sem que deste se exija contribuição onerosa; promover uma política salarial, que não degenere em fator inflacionário mas represente acréscimo do dade entre na sociedade de consumo, assegurando-Ihes a reciprocida vida, que expansão econômica e o progressivo acesso aos bens É nesse panorama ideal que se enquadram os Programas
do Ministério do Trabalho e Previdência Social, que é, por excelên.
cia, o Ministério do homem cia, o Ministério do homem.

Timbra, entretanto, o Governo em não seguir, na adoção e na prática desses programas, uma tendência paternalista, que nos conduziria a falsear a imagem do poder público, vendo nele a $\mathrm{Di}$ vina Providência, a solução única de todas as dificuldades.

Como se verá da exposição sucinta dos programas, todos R. Serv. públ., Brasilia, 109 (2) abr./jun. 1974 
de uma associação de energias, da formação de uma consciência nacional, que deve existir e florescer nos homens do Governo, nos empresários e nos trabalhadores, de tal sorte que cada um se capacite de sua responsabilidade perante a Pátria e dê o máximo de si mesmo ao esforço comum.

Mesmo porque nenhuma iniciativa de Governo será fecunda, se não tiver a participação, total e constante, daqueles a quem vai beneficiar.

\section{O PROGRAMA DE INTEGRAÇÃO SOCIAL (PIS)}

O PIS, instituído pela Lei Complementar n. 7 , de 7-7-1970, é fórmula original e nossa. Superior à da participação nos lucros. Tem sua finalidade a poupança acumulada para benefício simultâ. neo e permanente do empregado e das empresas. Estas e o Go. verno contribuem, em proporções que a lei estipulou realistica. mente, a fim de não redundarem em ônus exagerado, para um Fundo de Participação, no qual todos os empregados de todas as empresas são cadastrados e passam a possuir na Caixa Econô. mica Federal um pecúlio nominal, na proporção do seu salário e do seu tempo de serviço. Como do empregado nenhuma contribuição se exige, estamos diante de um mecanismo típico de trans. ferência de renda que serve à suplementação do ganho do assa. lariado, ao mesmo tempo que se destina a fornecer recursos no. Vos às empresas, mediante a concessão de empréstimos e finan. ciamentos. Por esse processo de reciprocidade fomenta-se a pro. dução, incrementando, sem perigo de inflacionar, o desenvolvi. mento econômico; e aumenta-se a renda "per capita" de milhões de brasileiros, os trabalhadores, com os juros ou dividendos re. sultantes da rentabilidade do Fundo, favorecendo-se, dessa maneira, o desenvolvimento social.

O PROGRAMA DE INTEGRAÇÃO SOCIAL, que arrecadou e aplicou, desde sua instituição, mais de 3 bilhões de cruzeiros já está produzindo uma renda anual de $21 \%$ sobre o pecúlio de cada trabalhador.

Em pouco mais de três anos após seu lançamento o PIS já cadastrou, em todo o País, dez milhões e oitocentos mil trabalhadores urbanos, que, pela primeira vez em sua vida, podem contar com a sua poupança.

A fim de que se possa avaliar os benefícios desse Programa em favor da constituição de um pecúlio para o trabalhador, bas. ta dizer que o valor médio desse pecúlio já alcançou uma impor- 
tância superior à do mais alto salário mínimo vigente no País. Este, como se sabe, no presente momento, é de Cr\$ 312,00 e o valor médio do pecúlio do PIS já é de Cr\$ 332,00.

Com a nova Lei Complementar, apresentada há pouco tempo ao Congresso Nacional e já aprovada na Câmara e no Senado, por unanimidade, aproveitando a circunstância de uma redução no ICM, conseguiu o Governo melhorar, ainda mais, o Fundo do PIS. Assim a partir do ano de 1975, esse pecúlio estará automaticamente acrescido de um mínimo de $30 \%$. Só com as medidas decorrentes dessa segunda Lei Complementar, teremos, no primeiro ano de aplicação da Lei, um acréscimo de um bilhão e duzentos milhões de cruzeiros para o Fundo do PIS e, no segundo exercício, quer dizer, de 1976 para 1977, se terá mais um acréscimo de dois bilhões e quatrocentos milhões de cruzeiros. Segundo o Ministério da Fazenda, que já fez as projeções
do PIS para os próximos anos, logo na primeira etapa do Governo que vai suceder ao do Presidente Médici, o Fundo do PIS que suibiria a sete bilhões e oitocentos e quarenta milhões de cruzeiros, com o acréscimo que adveio agora ultrapassará, nono total
os dez bilhões de cruzeiros.

Bastam esses números para mostrar o que esse Programa, de origem brasileira, representa, de fato, na promoção social do trabalhador. Mais do que isso, no dizer do Ministro Júlio Barata, é a sua participação efetiva na produção nacional. É a participação de todos os trabalhadores nos frutos do nosso progresso.

Para encerrarmos este capítulo sobre o PIS fomos buscar na imprensa nacional, mais precisamente em um de seus órgãos - o "CORREIO BRAZILIENSE" - um editorial, publicado a 9 de dezembro de 1973, que apreciando os programas do MTPS dá bem a medida do que o PIS representa para a economia do País e pa-
ra o trabalhador brasileiro.

\section{" O GRANDE PROgRAMA}

Há cerca de um ano, o PIS era tema de acirrados debates no Congresso Nacional, provocados pela oposição, que o considerava medida demagógica e sem qualquer influência no crescimento da renda "per capita", tomada esta quer no todo nacional, quer no que diz respeito à classe assalariada, em bloco e individualmente. Argumentava-se, primeiro, que o quinhão de cada cadastrado não estava sendo creditado em sua conta e, uma vez to. mada esta medida, tentava-se minimizar o alcance social do pro. R. Serv. públ., Brasília, 109 (2) abr./jun. 1974 
grama com o pequeno rendimento do primeiro ano. Segundo os oposicionistas, o que os trabalhadores precisavam eram de salá. rios que lhes permitissem uma poupança não forçada.

Esta ótica primária e imediatista foi evidentemente melhorada, pois o passar dos tempos revelou o incontestável alcance do Programa de Integração Social, que se revela de extraordinária flexibilidade. Tanto assim que as críticas cessaram ou foram estrategicamente desviadas para outros setores.

Esse fundo de reserva financeira dos trabalhadores, graças ao giro que the está sendo dado, vem crescendo como bola de neve que desce da montanha. O pequeno quinhão do primeiro ano aumenta de volume de tal modo que, já em fins de 1976, cada assalariado terá uma renda extra equivalente a um salário mensal. Será, com efeito, o décimo quarto salário. E nesse crescer geométrico pode avaliar-se o que representará para a imensa classe de trabalhadores que, em número superior a 10 milhões, já estão cadastrados. Torna-se, portanto, evidente, o papel do PIS no crescimen.
to da renda, não sendo exagero afirmar que, de todos os grandes programas planejados pelo Governo do Presidente Emílio Médici, este, da área do Ministério do Trabalho, é o de mais acentuado cunho social, vindo inovar num setor que há muito tempo vem sendo estudado neste e em muitos outros países do mundo, sem que se tivesse encontrado a solução ideal.

Com efeito, não é de hoje que se busca a perfeita associação do capital e do trabalho, não apenas nos resultados da produção, mas ainda na distribuição equânime dos resultados. Aqui no
Brasil em certa época conturbada, conturbadamente se falou na participação dos trabalhadores nos lucros das empresas. As boas idéias nã̃o comportam, no entanto soluções, demagógicas. Atento à realidade brasileira, o atual Governo, cuja imaginação deve ser, mais uma vez, destacada, deslocou a questão do plano do lucro para o plano do faturamento. O resultado foi o almejado há tanto tempo: o assalariado começou a participar, efetivamente, dos resultados financeiros da empresa.

Pormenor de suma importância é que essa nova fonte de renda do trabalhador constitui, simultaneamente, um precioso pecúlio. O PIS é, em conseqüência, mecanismo de poupança e de distribuição de renda, simultaneamente. É instrumento de aceleração da economia e multiplicador do quadro de empregados. Atende a área social e tem profundas repercussões na área eco. nômica. 
Tanto assim é que, mercê da sua versatilidade, acaba de ser aproveitado como mecanismo de compensação do ICM, no programa de redução gradual das alíquotas. Ganha, desse modo, uma nova faceta, qual seja a de contribuir para a minimização das diferenças regionais, depois de dar provas abundantes de sua força como instrumento de diminuição das diferenças sociais.

Por tudo isso, a presença do Ministro Júlio Barata na pasta do Trabalho ficará assinalada como um marco na nossa evolução social. Muitos e relevantes são os pontos positivos de sua ges. tão. Mas o Programa de Integração Social, por sua amplitude e pela influência que já exerce em outras áreas constitui o ápice de sua obra administrativa.

\section{PROGRAMA DE FORMACCÃO DO PATRIMONNIO
DO SERVIDOR PÚBLICO (PASEP)}

Não são, porém, apenas os trabalhadores das empresas industriais, comerciais e de serviços que gozam de tais benefícios. Outro Programa foi delineado pelo Governo Médici, e se encontra em plena execução, com o fito de elevar o nível de remuneração dos servidores civis e militares em atividade. É O PASEP ou "Programa de Formação do Patrimônio do Servidor Público".

A Lei Complementar $n .^{\circ} 8$, sancionada a 3 de dezembro de 1970, instituiu esse Programa, a respeito do qual, em mensagem ao Congresso Nacional, dizia o Presidente Médici :

"O Governo não compreende a prática de justiça social se. não em termos de distribuição da riqueza global e tudo pretende fazer para que o desenvolvimento econômico seja simultâneo com a promoção social dos trabalhadores e não dê ensejo à formação de castas ou classes privilegiadas, mas represente a oportunida. de para que o nível de poder aquisitivo dos assalariados os torne cada vez mais participantes da riqueza comum da Nação... Sobreveio, assim, consubstanciado na Lei Complementar n. ${ }^{\circ}$, o Progra. ma de Integração Social, destinado a promover a integração do empregado na vida e no desenvolvimento das empresas, que atuam na esfera dos negócios privados, com a conseqüente formação do Fundo de Participação, cujos reais benefícios se farão sentir no setor assalariado, não só da fruição de um patrimônio in. ção de estímulos e hábitos de poupança, formadores de uma men. talidade nova, indispensável ao nosso desenvolvimento econômico 
Com a mesma preocupação, com o mesmo ânimo que então me inspirou no sentido de atender a um dos mais relevantes interesses da população obreira do País, também agora, tão só in. formado pela idéia de justiça, tenho a honra de submeter aos Senhores Membros do Congresso Nacional, o presente projeto de Lei Complementar, que institui o Programa de Formação do Patrimônio do Servidor Público".

Como se infere das palavras do Presidente da República, - que se teve em mira, como no caso dos trabalhadores, foi assegurar a outro segmento da população "uma participação direta, cada vez maior, nos bens e utilidades criados pelo esforço coletivo do País".

O PASEP obedece aos moldes e ao estilo do PIS, para o benefício dos servidores civis e militares, cabendo a administração de seu Fundo ao Banco do Brasil. Mediante uma contribuição arrecadada mensalmente da União, dos Estados, dos Municípios, do Distrito Federal e dos Territórios, organiza-se um Fundo, cujos resultados são distribuídos, entre todos os servidores em atividade, civis e militares, $50 \%$ em proporção com o montante da remuneração de cada um e $50 \%$ em partes proporcionais aos quinqüênios de serviços prestados.

A simples análise da Lei Complementar $n .^{\circ} 8$ revela, mais do que a possibilidade, a certeza de que, doravante, os servidores públicos disporão de um pecúlio apreciável e receberão, anualmente, importâncias que poderão corresponder a um décimo terceiro vencimento.

lítica Para que se avaliem as perspectivas, a médio prazo, da pocorpa traçada pelo Governo Médici no sentido de assegurar a inde bração e maior participação de todos os setores da sociedade brasileira no processo de desenvolvimento, nada mais expres. sivo do que o pronunciamento de Jorge Restrepo, representante do Fundo Monetário Internacional, na reunião do CIAP, em 12 de junho de 1973. Confirmando impressões dos representantes da Agência para Desenvolvimento Internacional e do Banco Interamericano de Desenvolvimento, o $\mathrm{Sr}$. Jorge Restrepo salientou que "se esperam efeitos importantes na formação de poupanças para os trabalhadores através da operação de mecanismos financeiros com aportes do Governo e das empresas".

Em verdade, todas as formas de aumentar a renda real do as. salariado estão sendo procuradas e aplicadas pelo Governo, para que se faça convergir para o bem-estar social o progresso econô- 
mico, numa definitiva e salutar transfiguração da paisagem humana em nosso País.

O total arrecadado pelo PASEP do seu início até $31-12-73$ já é de $\mathrm{Cr} \$ 2.513 .049 .802,98$ dos quais foram aplicados . . . . . . Cr\$ 2.375.066.774,80 em investimento e empréstimo.

Até aquela data, o total de entidades cadastradas era de 5.353; sendo 3.372 da Administração Direta e $1.891 \mathrm{da} \mathrm{Ad-}$ ministração Indireta.

\section{PROGRAMA DE VALORIZAÇÃO DA AÇÃO SINDICAL}

O pensamento que norteia o Programa de Valorização da Ação Sindical é o de valorizar o trabalhador dentro da sua associa. ção de classe. Entre os instrumentos de que dispõe o Estado para a consecução dos objetivos da justiça social, figura, em lugar eminente, o sindicato. Valorizar-lhe a ação, purificando-o e fortalecendo-o, era, pois, um imperativo da Revolução de Março. Não seria jamais possível contemporizar ou compactuar com as idéias que viciaram no passado a atitude sindical. Pensar que 'o surgimento de centrais sindicais, a fusão de categorias profissionais heterogêneas e a intromissão das entidades representativas de classe na vida política pudessem servir a paz social e ao bemestar dos trabalhadores significaria, para nós, erro crasso, cujos efeitos é fácil prever no confronto com o que sucede em alguns países, onde o sindicalismo enveredou por aqueles caminhos.

A opção do Governo foi clara e firme, quando fez coincidir o fortalecimento do sindicato com a soma de serviços efetivos que ele pode prestar a seus associados.

O sentido do Programa de Valorização da Ação Sindical é este e seus rumos mostram que, sem desvirtuamento de tão altos propósitos, o panorama do sindicalismo brasileiro, rapidamente,

\section{FRUTOS DA PRIMEIRA ETAPA}

Não cabe aqui alinhar todos os itens do Programa de Valorização da Ação Sindical, sendo suficiente, para lhe medir o alcance, apontar os frutos, desde o dia em que foi implantado pelo Decreto Executivo 67.227, de 21 de setembro de 1970 .

Esses frutos se tornam visíveis, à medida que se promovem cursos de administradores sindicais; se instalam ambulatório médicos em sindicatos; se concedem empréstimos individuais R. Serv. públ., Brasilia, 109 (2) abr./jun. 1974 
a trabalhadores sindicalizados; se financia a construção de sedes, de colônias de férias, de centros de recreação, de piscinas e campos de esporte; se distribuem a filhos de trabalhadores bolsas de estudo e se integra, ainda o elemento sindical no esforço para errådicação do analfabetismo.

Numa sucinta amostragem, podemos assinalar a realização de Cursos de Administradores Sindicais no Distrito Federal, na Guanabara, no Rio Grande do Sul em Minas Gerais, Pernambuco Bahia e São Paulo. Atacando as áreas de maior densidade sindical, esses Cursos, com a duração de oito semanas, ministram conhecimentos gerais e especializados sobre Administração, Economia, Legislação Trabalhista e assuntos correlatos. Destinam-se à formação e capacitação de dirigentes, para o melhor desempenho de seus deveres à frente dos órgãos sob sua responsabilidade.

No tocante a empréstimos individuais, por meio de convênio com a Caixa Econômica, empréstimos a entidades, para os fins já expostos, foram autorizados até 1973 num valor total de 1 milhão e 769 mil cruzeiros.

Quanto à instalação de ambulatórios médicos e odontológicos em sindicatos, mediante convênios do INPS com os órgãos de classe, só no primeiro ano de funcionamento do Plano, 1972, conseguimos instalar 253 , à razão de quatro por semana, se já, agora, è de 600 o número de sindicatos que possuem, em suas sedes, esses serviços de assistência médica e social.

\section{RENOVAÇÃO DOS QUADROS SINDICAIS}

ra Assim orientada, a ação sindical entra numa fase redentora. O mais moderado otimismo nos autoriza a prever a renovação paulatina dos quadros sindicais, que se enriquecerão de elementos cônscios de seu papel de servidores de suas categorias proem harmonizar o capital e o trabalho.

Agora os trabalhadores são alertados, com franqueza e positividade, para o imperativo de se aperfeiçoarem em suas profissões para que se façam merecedores de uma remuneração mais alta. Este o límpido sentido do lema: Melhor trabalho = melhor salário.

fim Em todo o Brasil, esse lema ressoa como um chamado a cã̃o de que se organize o grande mutirão nacional para qualificação da mão-de-obra, para a proteção do operário contra os aciden- 
tes, para o cumprimento objetivo, em cada setor profissional, do ideal de valorização do homem.

Assim, podemos prever que o Programa, até o término de sua primeira etapa, significará melhoria real, numa pertinaz valo. rização para um mínimo de um milhão e meio de beneficiados .

\section{UMA COMPARAÇÃO QUE SE IMPÕE}

Até 1964 o único dever, de que se incumbiam os sindicatos, era o de, anualmente, apresentarem suas reivindicações salariais à Justiça do Trabalho, após uma Assembléia Geral, da qual. normalmente, apenas participava menos de $10 \%$ dos trabalhadores sindicalizados.

Afora isso, os sindicatos eram entidades a serviço da má política e faziam de si mesmos instrumentos de prestígio político. eleitoral.

Hoje, com o plano do Governo para a valorização da ação sindical, o sindicato é sobretudo um prestador de serviços, espe. cialmente os de assistência médica.

Com a valorização da ação sindical, os sindicatos, que hoje somam 6.247, se viram fortalecidos e foram guindados a situa. ções compatíveis com o importante papel por eles desempenhado em um regime de sadia democracia, a ponto de multiplicar o nú. mero de seus associados, todos, constitucionalmente, facultativos.

Todavia, é de se ressaitar, que não se pode fazer, sob forma compulsória, o recrutamento de trabalhadores, porque nossa Cons tituição não contém nenhum preceito de sindicalização obrigató. ria, já que "o direito de associação é livre".

Como ilustração, vale dizer o que nos parece ser.

\section{O SINDICATO IDEAL}

Como poderia o Sindicato servir àquele ideal do Governo Revolucionário é o que se tentará responder com clareza, com aquela clareza que Ortega y Gasset chamava de "cortesia do
pensador". A imagem do sindicato que se deseja é simples O Sindicato
como deve ser para que corresponda à sua função mais nobre R. Serv. públ., Brasília, 109 (2) abr./jun. 1974 
o de instrumento da justiça social deveria aparecer com três características essenciais :
a) deve ser um sindicato livre
b) deve ser um sindicato integrado
c) deve ser um sindicato de serviço.

Os três requisitos se interpenetram e fundem para gerar o
sindicato ideal.

com O primeiro requisito é a liberdade. Liberdade de associação ção a nossa Constituição prescreve. Mas liberdade de associagrupos ligado significa liberdade aos grupos anti-nacionais e aos grupos ligados à política partidária.

O Sindicato autêntico não poderá permitir jamais a infiltradem utilizar como arma para a desordem, a agitação, a catequese criminosa dos fanáticos, estipendiados pelo comunismo interna-
cional.

Nunca estaremos tão longe da verdadeira justiça social como quando transigirmos - o que não mais acontecerá no Brasil vizam a doutrina e a ação dos que, em nome da liberdade escravizam; em nome da igualdade, criam a casta privilegiada dos burocratas da tirania e, em nome da fraternidade universal, roubam,
violentam e matam.

das Liberto dessas algemas, o sindicato deve libertar-se ainda rio eleitoróles político-partidárias, pois o sindicato não é escritó. go eleitoral, nem os sindicalizados são massa de manobra no jo. e votos é. Valer-se do órgão sindical para conquistar clientela votos é degradar a função específica do sindicato. da justiça social é equisito para que o sindicato seja instrumento
ditegração nos órgãos do Poder Público. A legislacãa define o sindicato como órgão de colaboração
com o Poder Público. A colaboração se impõe, não sob a forma de
subserviêd subserviência política, de um lado, e de tutela paternalista, de outro. Essa colaboraçãáo equivale, sim, a um esforço conjunto, coescalado, em que as posiçõ̂es e as responsabilidades, dentro da cional.
cierárquica, se situam num plano alto - o do interesse na- 
Além disso, o Sindicato, como representação de uma categoria profissional ou de uma categoria econômica, é peça de uma engrenagem e funciona dentro de uma sistemática, marcada pela disciplina da vinculação hierárquica. Não se compreende, nem se justifica, outro tipo de integração senão o que entrosa os sindicatos com as Federações Sindicais de seu ramo e estas com as respectivas Confederações.

Outro processo integrativo acarretaria a desorganização do meio sindical, só servindo, talvez, como em recentes episódios da nossa História, para propósitos espúrios.

E finalmente, para atender os fins humanos da justiça so. cial, o sindicato deve constituir-se em verdadeiro prestador de serviço a todos os seus associados.

Aí estão as linhas gerais, que podem contribuir para a for mação da mentalidade sindical, dentro de um programa ideal. cujas vigas mestras já foram lançadas pela Constituição Brasilei. ra e estão sendo sustentadas pela Revolução de 31 de Março.

\section{O PROGRAMA NACIONAL DE VALORIZAÇÃO DO TRABALHADOR (PNVT)}

Coroando e completando o Programa de Valorização da Ação Sindical, surgiu o Programa Nacional de Valorização do Tra. balhador.

Esse Programa, ao ser lançado pelo Decreto 70.861 , de 25-7-72, mereceu os seguintes comentários elucidativos :

"É um passo a mais, calculado e firme, no rumo do capita. lismo do grande número, que o Governo fixou como meta suprema em seu Plano de Desenvolvimento Econômico e Social.

Fácil seria, se nos animassem propósitos demagógicos. traçar planos de fachada, imponentes na aparência, inexequíveis na prática. Não menos fácil, também, seria acenar ao trabahador com uma dádiva a mais, ofertada pelas mãos paternais da autoridade. A linha severa de combate à demagogia e ao paternalismo não se compadece com tal estilo governamental.

Por isso, o Programa de Valorização do Trabalhador é mais uma súmula de deveres do que um elenco de direitos.

Deveres do Governo, que racionaliza o emprego de verbas do MTPS, de outros Ministérios e entidades.

R. Serv. públ., Brasilia, 109 (2) abr./jun. 1974 
Deveres dos Sindicatos que, mais uma vez, são convoca. dos para uma ação efetiva em prol de seus associados.

Deveres dos empresários, para os quais o surto de progres. so, controle da inflação e o sadio crescimento da indústria e do comércio constituem a melhor oportunidade para que se humanize a economia e se promova a distribuição gradual e equânime da rí queza comum".

As diretrizes traçadas pelo citado Decreto $n .^{\circ} 70.861$, que determinou prioridade quanto à política de valorização e aperfeiço. amento do trabalhador, teve sua programação estabelecida pela Portaria MTPS 3.236, de 27 subseqüente, que instituiu o PROGRA. MA NACIONAL DE VALORIZAÇÃO DO TRABALHADOR, incorpo. rando alguns programas que já se encontravam implantados. Suas metas, fixadas para o período $1972-74$ abrangem o treinamento de trabalhadores adultos carentes de qualificação profissional; concessão de 707.755 bolsas de estudo de $1 .^{\circ}$ e $2 .^{\circ}$ graus e de cerca de 15.000 bolsas para a formação técnica, em benefício dos trabaIhadores sindicalizados ou de seus dependentes; preparação de 13.839 profissionais de níveis superior e médio para controle da segurança e higiene do trabalho. Promoverá, ainda, o PNVT, opor. tunidade para 258.810 trabalhadores ou seus dependentes se al. fabetizarem e se aperfeiçoarem em conomia doméstica e educa. ção cívico-trabalhista.

No programa estão incluídos, ainda, dois projetos : 1) Diagnóstico do Mercado de Trabalho e 2) Cadastro Brasileiro de Ocupações-CBO, deste, a 1. ${ }^{\text {a }}$ edição, parcial e provisória, foi publicada em 1971, prosseguindo-se o levantamento de dados. Com o objetivo de se criar uma equipe de formação básica de analistas, para pesquisas de campo e organização e execução de análises dos postos, foi realizado em 1973, um curso ministrado por perito do PNUD.

nicos Esse Projeto conta ainda com a colaboração de Grupos Técórgão Consultivos, integrados por profissionais de alto nível de órgãos públicos e entidades privadas.

\section{TREINAMENTO INTENSIVO DE TRABALHADORES}

Os projetos relativos ao aperfeioçamento profissional de meio milhão de trabalhadores já têm convênios celebrados, para treinamento, com entidades como SENAI, o SENAC, Escolas Técnicas Federais, Estaduais e Municipais, com participação, ainda, do MEC - Ensino Industrial, do Conselho Nacional de Recursos 
Humanos, do Ministério do Exército e outros órgãos da Adminis. tração, além de empresas privadas

O Projeto Caxias - convênio com o Exército, que se encarrega do treinamento de conscritos, está sendo ampliado, a fim de alcançar o maior número possível de beneficiários.

O Projeto PISCES, destinado à pesca, e de interesse do Mi. nistério da Marinha, já tem convênio celebrado no Rio Grande do Sul.

Em consonância com a política de valorização e aperfeiçoa. mento do trabalhador são desenvolvidos, pela Administração In. direta vinculada à Pasta do Trabalho e Previdência Social, progra. mas específicos de aperfeiçoamento, quer na área da reabilitação de segurados incapacitados ou na recuperação de pessoas margi. nalizadas por fatores sócio-econômicos.

A instituição pela Portaria MTPS 3.131 , de 18-4-73, das Co. missões Regionais de Planejamento Integrado, criadas especialmente com vistas ao desenvolvimento do PNVT, veio abrir novas perspectivas para sua expansão e dos demais programas do MTPS, possibilitando uma atuação harmônica dos órgãos do MTPS situados nos Estados.

\section{FINS E MEIOS DO PNVT}

O Presidente da República, ao assinar o Decreto n. 70.861 , fixou diretrizes e linhas de ação, que fazem parte da estratégia global, visando ao paralelismo do desenvolvimento social com o desenvolvimento econômico.

O Plano Nacional de Valorização do Trabalhador, como afirma o Ministro Júlio Barata, é um plano que tem em mira solucionar, a médio prazo, o problema do emprego, do subemprego e do
desemprego.

A exemplo, a Delegacia Regional do Trabalho em Brasília oferece, em média por mês, mil e quatrocentos empregos, novos. Não consegue preencher nem mil desses empregos por falta de qualificação profissional, o que se constitui em um sério problema do Brasil. A única solução que se pode encontrar para ele, é a qualificação da mão-de-obra. Para elevar o nível salarial e para fazer com que o candidato ao emprego encontre no mercado de trabalho a ocupação e a remuneração de que precisa, é necessário qualificar a mão-de-obra. Esse esforço de formação profissio. nal é nosso esforço mais importante.

R. Serv. públ., Brasília, 109 (2) abr./jun. 1974 
Ao Departamento Nacional de Mão-de-Obra do MTPS cabe a execução do PNVT, em função dos objetivos visados, que seriam, numa primeira etapa, atingir se possível, o número de um milhão e quinhentos mil trabalhadores qualificados.

É ainda o Prof. Júlio Barata, agora, textualmente, quem diz :

inclusivara que se veja a importância do problema do emprego, lembrasive, no tocante à distribuição de renda, eu me permitiria da Indús discurso recente do Deputado Daniel Faraco, ex-Ministro zia: "o grande do Comércio, no qual esse ilustre parlamentar dição de renda é o emprego. Independentemente de sua fanção ditribuidora é o emprego. Independentemente de sua função dis. tes do País, por uma série de razões. De um lado, temos os jovens que, anualmente, se incorporam à população trabalhadora, em busca de colocação; do outro, temos a mão-de-obra liberada pelos modernos processos de agricultura". E eu acrescentaria e pela introdução da tecnologia - porque há uma correlação, em sentido negativo, entre o incremento da tecnologia e o número de empregos disponíveis. A tecnologia é uma fonte de desempre. go, na maioria dos casos". Discorrendo, ainda, sobre o PNVT te. ve o Prof. Júlio Barata o ensejo de revelar que:

"Temos um instrumento de controle do emprego, no Brasil, que é fornecido pelo Fundo de Garantia por Tempo de Serviço. A inscrição no Fundo de Garantia de um lado, e a inscri-
forno novos contribuintes no Instituto de Previdência Social nos fornecem elemento para uma estatística que mostra a maneira pela qual esse problema vai evoluindo dentro do Brasil, problema jáse que foi por mim focalizado em nome do Governo Brasileiro, já por três vezes, na Conferência Internacional de Genebra, quan. zar o Cendemos. Como tese brasileira, a necessidade de liberali. zar o Comércio Internacional para que se multiplique o número de empregos nos países em desenvolvimento".

\section{RESULTADOS RECENTES}

Se o programa de Metas e Bases para a Ação do Governo já previa no início até 1970 a necessidade de preencher, em média, oitocentos mil empregos novos por ano no Brasil, verifica-se que, segundo a última estatística apresentada ao MTPS, estatística essa oriunda da confrontação de dados do Fundo de Garantia por Tempo de Serviço e das novas inscrições dos últimos $12 \mathrm{me}$. ses no INPS, o aludido índice foi superado. Assim, a estatística 
revela que foram exatamente, oitocentos e oitenta e oito mil os empregos novos que o Ministério do Trabalho, graças ao PNVT, conseguiu dar àqueles que foram qualificados, ou que apresentaram qualificação suficiente para exercerem determinado ofício.

O PNVT, dentro da filosofia de ação do Governo Médici, possibilitou o encaminhamento, racional e dinâmico, das soluções que, em moldes brasileiros, se deseja encontrar para que o mer. cado de trabalho chegue, brevemente, ao regime de pleno empre. go. Esta, certamente, será uma das tarefas de maior relevo do Ministério do Trabalho e Previdência Social, em futuro próximo.

\section{PROGRAMA DE VALORIZAÇÃO DO TRABALHADOR RURAL}

Mas o programa que, no momento, vem empolgando a $\mathrm{Na}$ ção e equivale a uma autêntica revolução no campo, é o Programa de Valorização do Trabalhador Rural ou PRORURAL, de que trata a Lei Complementar $n .^{\circ} 11$.

Basta percorrer as zonas rurais de nosso País e entrar em contato com os operários do campo, para concluir que estamos às vésperas de uma profunda transformação, há longo tempo deseja. da e só agora conseguida.

O trabalhador rural era um enteado da nossa sociedade, abandonado e esquecido. Os inimigos da Pátria, sectários de doutrinas espúrias, pensaram encontrar no meio rural o caldo de cultura para os seus desígnios subversivos.

A Revolução, todavia, não se descurando desse problema, em seu terceiro governo ergueu a mais alta barreira contra essa tentativa criminosa e, ao instituir o PRORURAL integrou na comunidade nacional, e para sempre, o brasileiro do campo, conferindo-lhe o status a que ele tinha direito.

\section{FUNDAMENTOS DA LEI COMPLEMENTAR N. 11}

Os fundamentos da Lei Complementar n. 11 , de 26 de maio de 1971, demonstram que não foram simples promessa as palavras do Presidente Médici em seu discurso de posse.

Ao submeter ao Congresso Nacional o respectivo projeto de Lel, acentuava o Chefe da Nação ser chegada a hora de a cida. de ajudar o campo como o campo vinha, havia muito, ajudando a cidade. Para corrigir o desequilíbrio entre as populações rurais e R. Serv. públ., Brasília, 109 (2) abr./jun. 1974 
as populações urbanas, impunha-se dar àquelas um tratamento justo, ainda que esse ato de justiça custasse para estas algum sacrifício. Se do campo, onde mourejam cerca de quinze milhões de brasileiros, provém o alimento da massa populacional do País, e se, na pauta de nossas exportações, os produtos agrícolas figuram em lugar de destaque, não se compreende que o homem do campo continuasse proscrito dentro de sua própria terra e não gozasse da proteção e do amparo dispensados aos demais trabalhadores.

Entretanto, para que se cumprisse o desideratum de nivelar estratos sociais do campo e da cidade, não seria prudente nem avisado abalar a economia agrária, cedendo à pressão demagógica dos que pleiteiam uma reviravolta súbita e radical.

A Lei Complementar n. 11 é, por essas razões, um exem. plo de sensatez e de critério realista, a inaugurar uma fase nova de nossa história, em que se dá o máximo que se pode dar, dentro das possibilidades e recursos existentes, àqueles que, antes, nada tinham.

Retribuição com que pagamos, os habitantes da cidade e os proprietários rurais, o diuturno esforço e o humilde sacrifício do homem do campo. Redistribuição com que transferimos, gradati. vamente, para o homem do campo, a renda por nós auferida gra. ças a seu anônimo trabalho na lavoura. $E$ que os recursos cana. lizados para o PRORURAL resultam de uma taxa sobre as opera. ções de venda dos produtos agrícolas, taxa que onera os proprie. tários rurais e os consumidores urbanos.

No PRORURAL, temos assim o mais claro, o mais irrecusável, o mais típico modelo da renda distribuída com justiça, uma vez que o trabalhador rural passou a gozar dos benefícios da apo. sentadoria, da pensão e da assistência médica e odontológica, sem que dele se exigisse contribuição alguma. Foi a fórmula encontrada pelo Governo Médici para valorizar o trabalhador rural, enquanto não se pode dar a essa classe de operários todos os Cursos de aperfeiçoamento profissional que se fazem necessá.
rios.

\section{REGULAMENTAÇÃO E EXECUÇÃO DA LEI}

Regulamentada a Lei Complementar n..$^{\circ} 11$, sua execucão está a cargo do FUNRURAL, ou Fundo de Assistência ao Trabalha- 
dor Rural, dotado de personalidade jurídica cujo orçamento próprio garante o cumprimento de todas as obrigações a ele atribuí. das.

\section{ATUAÇÃO DO FUNRURAL EM TODO O PAÍS}

A atuação do FUNRURAL prevê não só a prestação previdenciária de aposentadorias e pensões, ao homem do campo, como assistência médico-hospitalar, cirúrgica, ambulatorial e odontológica, através de convênios com instituições especializadas. Com esses serviços despendeu o FUNRURAL em 1973 a importân. cia de Cr\$30.297.700,00 e com as doações em matérial feitas a hospitais, ambulatórios e consultórios dentários, a soma de Cr\$39.899.784,50.

\section{EFEITOS SOCIAIS DO AMPARO AO TRABALHADOR DO CAMPO}

Já é tempo, agora de os trabalhadores do campo saberem e sentirem que é no seu rumo também que se voltam as grandes e graves preocupações do País.

Em primeiro lugar, eliminou-se o complexo de inferiorida. de que marcava o homem do campo. O ambiente rural se vê im. pregnado de natural euforia, uma vez que a velhice do trabalhador do campo deixou de ser o triste epílogo de uma dura existência.

Aposentado, ele conta, todos os meses, sob o ponto de vis. ta financeiro, com uma importância, em dinheiro vivo, que ele não conseguiu economizar em todo o curso de sua vida. O seu novo poder aquisitivo ainda que em proporções modestas, o in. corpora, sob o ponto de vista social, à sociedade de consumo, facultando-Ihe o acesso a bens da vida antes inatingiveis e concor. re também para a expansão do mercado nos meios rurais.

Sob o ponto de vista psicológico, ele sabe que, ao fim da vida, sua família não ficará ao desamparo, graças à pensão que o PRORURAL garante a seus dependentes.

\section{AS ESTATÍSTICAS DO PRORURAL}

O PRORURAL, cujo funcionamento se iniciou a $10^{\circ}$ de maio de $1972 \mathrm{com}$ a entrega dos primeiros carnês de aposentadoria aos trabalhadores rurais até o presente momento já aposentou, segun. do estatísticas, levantadas pelo FUNRURAL, órgão executor do R. Serv. públ., Brasilia, 109 (2) abr./jun. 1974 
Programa, um milhão de trabalhadores rurais. O último destes, ou seja, o milionésimo, recebeu das mãos do Presidente Médici o seu carnê de aposentadoria.

\section{POLITICA SALARIAL}

Como fontes de apoio para seu Programa de Valorização do Trabalhador, precisou instituir o Governo um Plano de Ação Eco. nômica do Governo com as seguintes diretrizes fundamentais :

a) contenção progressiva dos deficits governamentais;

b) aumento dos salários subordinados ao aumento real da produtividade;

c) crédito controlado às empresas, para impedir os exces. sos da inflação de demanda;

No que se refere ao problema salarial, a primeira medida constituiu em estabelecer linhas mestras de uma orientação a ser seguida, cujos princípios básicos são :

a) manter a participação dos assalariados no Produto $\mathrm{Na}$ cional;

b) impedir que reajustamentos salariais desordenados realimentem irreversivelmente o processo inflacionário;

c) corrigir as distorções salarais particularmente no Serviço Público Federal, nas Autarquias e nas Sociedades de Economia Mista controladas pela União.

da Foi baixada então a Circular n. ${ }^{\circ}$ 10, de 19 de junho de 1964, da Presidência da República, cujos pontos principais são os se-
guintes:

lar 1 - O salário reajustado será determinado de modo a iguacado salário real médio vigente nos últimos 24 meses, multiplicado, a seguir, por um coeficiente que traduza o aumento da produtividade estimado para o ano anterior, acrescido da provisão para compensações de resíduo inflacionário.

dent 2 - Expressão do salário de cada um dos 24 meses precedentes em moeda de poder aquisitivo do mês em que se procevida.

tame 3 - Espaçamento mínimo de 12 meses entre dois reajus. 
Outra medida foi a reorganização do Conselho Nacional de Política Salarial (CNPS) através do Decreto n. 54.018 , de 14 de julho de 1964, ao qual coube autorizar os reajustamentos salariais de natureza coletiva :

a) das sociedades de economia mista sob a jurisdição do Governo Federal, o financiadas por bancos oficiais de investimento;

b) das empresas privadas subvencionadas pela União, ou concessionárias de serviços públicos federais, condicionando à sua audiência a concessão de aumento da sub. venção ou reajustamento de tarifas para atender a aumentos salariais.

Aí acham-se consubstanciados os objetivos colimados pela política salarial os quais podem ser assim resumidos :

a) reconstituição do salário real médio da categoria profissional, apurado nos últimos 24 meses anteriores à data do reajuste;

b) provisão para compensações do resíduo inflacionário admitido para o período de um ano na programação financeira do Governo;

c) incorporação de taxa concernente ao aumento da produtividade nacional no ano anterior.

O processo preconizado na política salarial não visa, apenas, à reconstituição do poder aquisitivo dos salários, conforme pode parecer à primeira vista. Objetiva, também, defendê-lo contra uma eventual elevação do custo-de-vida nos doze meses seguintes à revisão salarial.

\section{SALÁRIO MÍNIMO}

Os primeiros níveis de salário-mínimo tiveram a sua fixação em 1940, quando o valor do maior salário-mínimo vigente em todo o Território Nacional estava representado por Cr\$ 0,24, e o menor por Cr\$ 0,90 . Prevalecia então uma escala de 14 níveis diferen. tes. Em 1943 foram revistos pela primeira vez seus valores, oca. sião em que os níveis se elevaram a 21 , logo a seguir reduzidos, no mesmo ano, a 16.

Ao contrário do que se verifica nos dias atuais, a tendência de outrora era de diversificar os níveis. Houve época em que vigoravam no País 39 níveis diferentes. Logo após iniciou-se o de- 
clínio. Em 1960 subsistiam 15 níveis; em 1964 reduziu-se esse número a 11, depois a 9 em 1969, a 7 em 1970, 6 em 1971, 5 em 1972 e 5 em 1973. De seu turno, a relação entre o maior e o menor valor do salário-mínimo vem se estreitando no curso do tempo, tendo passado de 4,33 (1954) para 1,46 (1973).

Entende o Governo que a unificação dos níveis de saláriomínimo afigura-se, sob certos aspectos, recomendável. Mas reco. nhece que esse objetivo somente poderá ser atingido por etapas, mediante um processo de aglutinação progressiva, à medida e na proporção em que se forem atenuando as disparidades regionais. A fixação de níveis divorciados das condições e possibilidades econômicas locais repercutiria de modo tanto mais desfavorável quanto menos desenvolvidas as regiões que se pretende benefileis. A imposição de níveis salariais, em flagrante desrespeito às acarretar as mais danosas conseqüências à população, em ter. mos de desemprego, de redução de ritmo de atividade, de menor oferta de bens e serviços, de aumento de preços e de tensões so-
ciais.

É fato sabido que o aumento nominal dos salários, se desa. companhado da redução da taxa do custo de vida em escala equivalente, em breve passa à constituir mais um motivo de desilu. são. Ninguém ignora que o aumento salarial, feito acima dos limites suportáveis pela economia, deflagra, mais cedo ou mais tarde, uma forte tensão nos preços dos bens e serviços. Se nessa época a inflação de custo prepondera sobre a inflação de de. manda, certamente ocorrerá uma retração na procura daqueles mesmos bens e serviços. A situação ainda mais se agravará se a aceleração do processo inflacionário assumir caráter persistente, caso em que se passa a viver sob a constante ameaça de uma re. cessão na economia com o fantasma do desemprego rondando as áreas mais duramente atingidas pelo processo.

Devido a esses motivos está o Governo mais empenhado em valorizar o salário real através do combate à inflação e da transferência de ganhos do aumento de produtividade, do que em praticar uma política demagógica apoiada em aumentos exclusivamente nominais, que só desservem ao País.

\section{SALÁRIO SUPLEMENTAR}

Uma das finalidades que caracterizam o comportamento do atual Governo em face do trabalhador é a ampliação do salário in. direto ou suplementar. O esforço para alcançálo resulta de uma 
conjugação de atividades no âmbito do MTPS e fora dele, dentro do princípio de que o Governo é uno, integrado, coeso, e contínuo, devendo sempre funcionar sob o espírito de equipe.

Vem por isso se empenhando em promover a distribuição da renda pela população em geral, recorrendo a todos os meios ao seu alcance, sobretudo aos denominados benefícios indiretos, dentre os quais se destacam : a democratização do ensino por intermédio da concessão de bolsas de estudo aos filhos dos trabaIhadores; a melhoria dos serviços de assistência social; a aquisição da casa própria através de financiamentos oficais; a integração dos sindicatos nos programas de desenvolvimento social em favor do trabalhador do campo da educação, saúde, etc.; instituição de formas de acesso ao crédito, inclusive empréstimos sim. ples; o Programa de Integração Social e o Programa de Formação do Patrimônio do Servidor Público, e o fornecimento de remédios (CEME) para mencionar as mais recentes iniciativas do Go. verno em benefício dos assalariados em geral.

Quanto às vantagens indiretas, oferecidas aos trabalhado. res, as bolsas de estudo constituem uma iniciativa fecunda, de resultados incontestáveis.

\section{PROGRAMA ESPECIAL DE BOLSAS DE ESTUDO (PEBE)}

Instituído em 1966, o Programa Especial de Bolsas de Estudo - PEBE do MTPS vem desenvolvendo intenso e produtivo tra. balho no campo da educação geral e da formação profissional.

O PEBE tem como objetivo primordial a concessão de bol. sas de estudo, através dos Sindicatos, a trabalhadores sindicaliza. dos e seus dependentes, que estejam matriculados nos cursos de $1 .^{\circ}$ e $2 .^{\circ}$ graus.

Desde sua criação, até o presente momento, foram distri. buídas 900 mil bolsas de estudo, num valor total de 270 milhões de cruzeiros.

As bolsas representam um benefício da mais alta relevân. cia social, porquanto vêm beneficiar, de maneira decisiva, a um enorme contingente de trabalhadores, contribuindo para sua for mação cultural e profissional e, por conseguinte, para a elevação do nível social na comunidade a que pertencem.

O Programa Especial de Bolsas de Estudo conta, atualmen. te, com 7 projetos específicos, e em pleno funcionamento, abran R. Serv. públ., Brasilia, 109 (2) abr./jun. 1974 
gendo uma gama variada de benefícios aos trabalhadores sindica. lizados, que vão desde a concessão de bolsas para ensino supletivo (antigo madureza), a bolsas para os cursos técnicos de $2 .{ }^{\circ}$ grau.

Em 1973 foram concedidas 191.475 bolsas de estudo com a despesa total de $\mathrm{Cr} \$ 31.294 .175,00$.

\section{SEGURANÇA E HIGIENE DO TRABALHO}

O MTPS através do seu Departamento Nacional de Seguran. ça e Higiene do Trabalho intensificou estudos cometidos em Lei, sobre as condições para o trabalho de menores de doze a quatorze anos, objetivando preservar-lhes a saúde e garantir-lhes bem. estar. Em seguida foi dada ênfase à prevenção de acidentes, tendo em vista o acelerado desenvolvimento industrial.

O trabalho da mulher e do menor tem sido sempre objetivo do interesse do MTPS, que leva a efeito permanente estudos e investigações, com o fim de aperfeiçoar e atualizar as normas de caráter técnico e leis específicas da sua proteção.

O Ministério esteve representado no seminário realizado em Buenos Aires, organizado pela Secretaria-Geral da Organização dos Estados Americanos, quando apresentou o trabalho intitula. do: "Problemas da Mulher que Trabalha - Medidas Adotadas pelo Governo para Resolvê-los", considerando muito importante pelo seu caráter informativo, já que o trabalho da mulher, atualmente, é imprescindível à dinâmica do progresso de qualquer país, não só em termos de potência, mas como elemento básico de fortalecimento do equilíbrio social.

Com vistas ao desenvolvimento das metas estabelecidas no PNVT, o Ministério firmou convênio com o INPS e com a Funda. ção Centro Nacional de Segurança e Higiene do Trabalho FUNDACENTRO - para especialização profissional em níveis mé. dio e superior, com vistas ao controle da higiene e segurança do trabalho.

No exercício de 1973 foi realizado o XII Congresso de Pre. Venção de Acidentes do Trabalho, em Guarapari, no Estado do Es. pírito Santo, cujos temas foram os seguintes: "Segurança e Higiene do Trabalho nas Atividades de Mineração de Ferro"; Técnicas de Investigação de Acidentes do Trabalho" e "Atualização das Co. missões Internas de Prevenção de Acidentes - CIPAS". 
A profissionalização em níveis médio e superior para as áreas da segurança e higiene do trabalho, executada através da Fundação Centro Higiene, Segurança e Medicina do Trabalho, sob a supervisão do DNSHT, teve sua $1 .{ }^{\text {a }}$ etapa realizada com a formação de professores, elaboração de currículos e sondagens junto às Universidades que pudessem participar desse aperfeiçoamento.

\section{GRUPO TAREFA DA AMAZÔNIA — GTA}

Os programas que o Ministério do Trabalho e Previdência Social se propôs a cumprir, e está cumprindo, partem do princípio de que a justiça social deve englobar os grupos sociais nos frutos do desenvolvimento econômico. Constituem eles um elenco de realizações que, inclusive, já alcançou repercussão internacional, notadamente o PROGRAMA DE INTEGRAÇÃO SOCIAL e o PRO. GRAMA DE ASSISTENCIA AO TRABALHADOR RURAL.

Comprovando essa gama de realizações estendeu o MTPS sua atuação à Amazônia, de maneira a amparar o trabalhador se. diado na Transamazônica e na Perimetral Norte.

Atua o MTPS na região da Transamazônica e Amazônia Le. gal desde setembro de 1970, como um dos principais suportes à realização do PROGRAMA DE INTEGRAÇÃO NACIONAL-PIN, através de iniciativas postas em prática nos vários setores de sua estrutura administrativa, tanto da administração direta como indireta.

Com a expedição da Portaria MTPS 3.081 , de 17 de março de 1971, foi criado o Grupo Tarefa da Transamazônica com atribuições de coordenação de todos os planos, tarefas e encargos preconizados pelo PIN.

O GTA iniciou suas atividades levantando as condições mé. dico-hospitalares ao longo das rodovias da região, localizando os pontos onde deveriam ser construídos os hospitais de apoio e os conjuntos residenciais, verificando, também, as possibilidades da celebração de convênios hospitalares e de treinamento profissional visando à criação da infra-estrutura necessária à consolidação
do PROGRAMA.

Ao longo das rodovias e em pequenos povoados e vilas da região, foram postos em circulação 18 ambulatórios Médicos Vo. lantes, montados em ônibus, os quais contam com subsídio mensal para consulta médica, atendimento odontológico, pequena cirurgia 
e assistência a parturientes. Por força de convênio, a CEME fornece os medicamentos de que carece essa população.

Atuando na Amazônia Legal encontra-se o subgrupo Volante de Inspeção do Trabalho - (Portaria - MTPS n. 3.076 , de 15.03.73 e 3.106, de 30-04-73) - Com encargos de orientar e fiscalizar o cumprimento dos preceitos trabalhistas, dos convênios de âssistência médico-odontológica, firmados pelo INPS, FUNRURAL e IPASE e também dos convênios referentes ao PNVT. $\mathrm{O}$ apoio à mão-de-obra vem sendo fornecido através das
Agências de Colocação e Postos de Identificação Profissional das cidades do Marabá, Altamira, Santarém, Itaituba e Monte Dourado, no Pará, Humaitá, no Amazonas; Balsas, S. João dos Patos e Carolina, no Maranhão; afora os órgãos regionais de maior porte existentes nas capitais dos Estados e Territórios.

$\mathrm{O}$ número de carteiras profissionais expedidas se situa em torno de 30.000; aliás é de se esclarecer que, através da Portaria MTPS 3.279 , de $10-09.73$, foi implantada a CARTEIRA PROFISSIO. NAL PROVISÓRIA, vigente por um ano, limitada à área da Amazô. nia legal. Com essa medida, trabalhadores adultos e menores, de ambos os sexos, ficarão ao abrigo da legislação trabalhista, recebendo amparo médico-assistencial e previdenciário.

cial O adestramento da mão-de-obra recebeu tratamento espepal e o treinamento realizado destina-se à área primária, principalmente. Está sendo executado através de convênios com a SULAM, Secretarias de Agricultura, INCRA, ACAR, outros órgãos federais e estaduais e empresas particulares.

vênio Com a Mercedez Benz do Brasil S. A. foi realizado um conDiesel para instalação de um Centro de Treinamento de Mecânica co de formação e outros de mecânica de automóveis. Este convê. nio deve ser estendido a outras áreas da Amazônia, encontrando. se em fase de implantação.

Com o BNH foi celebrado convênio com vistas ao treinamento para construção civil, com a SUDAM - para Operadores de moto-serra, de classificadores de produtos agrícolas e tam. rio para Supervisores; com as Diretorias Estaduais do Ministério da Agricultura, o treinamento se refere à Vacinação, Manejo, Alimentação e Higiene do Gado, Culturas de Subsistência, Mecanização para Líderes Agrícolas, e outros da mesma área. Com o INCRA visou o treinamento em moto-serras e em Prática de Agricultura e Pecuária, com alta qualificação.

R. Serv. públ., Brasília, 109 (2) abr./jun. 1974 
No exercício de 1972 foram treinados 6.754 trabalhadores em atividades da faixa primária, destinados à colonização. No ano corrente de 1973 acham-se em funcionamento 195 Cursos, com um total de 10.476 trabalhadores em treinamento.

\section{CONCLUSÃO}

Ao término deste artigo, verifica-se que ele foi apenas um resumo retrospectivo e, como tal, incompleto, das atividades do MTPS na área do trabalho.

Enfatizando a valorização do homem, invocamos pronunciamentos do Prof. Júlio Barata. Nada mais lógico que invocarmos ao final, palavras suas para sintetizar, a perfeição que se preten. dam evidenciar neste retrospecto.

"As pedras fundamentais foram lançadas. São os Progra. mas, que mencionei. Mas esses Programas, fruto de um planejamento realista, acordes com a filosofia social da Revolução de Março, não ficam limitados aos textos das leis e decretos, que nos traçaram diretrizes e linhas de ação. Todos esses Programas estão sendo executados, em ritmo acelerado, com o dinamismo, que nos permitem os recursos financeiros e humanos, e com o entusiasmo que nos enche a alma brasileira sempre que cuidamos de valorizar o homem, isto é, de ajustar o nosso homem às dimensôes do Brasil".

"Os Brasileiros de hoje, integrados no espírito de uma Re. volução redentora, cultivamos a esperança, não a esperança dos utopistas, mas a esperança dos que sabem medir, calcular e prever com realismo, com prudência, com sensatez e com fundamen. to, o tamanho material e moral do Brasil de amanhã.

Ao clarão dessa esperança, racional, e pura, não duvida. mos de que os Programas planejados e executados pelo Ministé rio do Trabalho e Previdência Social, sejam um impulso decisivo e certo na direção de uma Pátria mais rica, mais forte e mais feliz". 